The mobilizing effect of right-wing ideological climates:

Cross-level interaction effects on different types of outgroup attitudes

Jasper Van Assche, Arne Roets, Jonas De keersmaecker, \& Alain Van Hiel Department of Developmental, Personality and Social Psychology, Ghent University

Paper published in Political Psychology

Van Assche, J., Roets, A., De keersmaecker, K., \& Van Hiel, A. (2017). The mobilizing effect of right-wing ideological climates: Cross-level interaction effects on different types of outgroup attitudes. Political Psychology, 38(5), 757-776.

Corresponding author:

Jasper Van Assche

Department of Developmental, Personality and Social Psychology

Faculty of Psychology and Educational Sciences, Ghent University

Henri Dunantlaan 2, B-9000 Ghent (Belgium)

E-mail: Jasper.VanAssche@UGent.be

Telephone: +3292646424

Fax: +329 2646499

Word count: 9652

Key words: right-wing attitudes, right-wing climate, prejudice, multilevel context

Running head: Mobilizing effects of right-wing climates 


\begin{abstract}
The present research investigated a multilevel person-context interactionist framework for the relationship between right-wing ideologies and prejudice across two large, representative samples (Study 1: European Social Survey: $N=56,752$; Study 2: World Values Survey: $N=74,042$ ). Across three different operationalizations of right-wing ideology, two contextual levels (regional and national) of right-wing climate, and three types of outgroup attitudes (i.e., age-, ethnicity-, and gender-based), the analyses consistently revealed crosslevel interactions, showing a strong association between right-wing attitudes and negative outgroup attitudes at the individual level in contexts with a low right-wing climate, whereas this relationship is weaker and often even absent in contexts with a high right-wing climate. These cross-level interactions remained significant after controlling for statistical artefacts (i.e., restriction of range and outliers). The authors propose norm setting as the mobilizing mechanism through which a right-wing climate develops and curbs the influence of individual right-wing social-ideological attitudes on outgroup attitudes.
\end{abstract}




\section{The mobilizing effect of right-wing ideological climates: Cross-level interaction effects on different types of outgroup attitudes}

Research on negative outgroup attitudes and its determinants has been on the forefront of scientific research in social psychology since the 1950s (e.g., Allport, 1954). Several personality traits and social-ideological attitudes have been proposed as important bases of how people think and feel about outgroups, such as authoritarianism (Adorno, FrenkelBrunswik, Levinson, \& Sanford, 1950), tough-mindedness (Eysenck, 1954), power distance (Hofstede, 1980), and conservation (Schwartz et al., 2001) (for an overview, see Duckitt \& Sibley, 2010). Contemporary psychological research has proposed two broad socialideological attitudes that influence outgroup attitudes in different ways (Duckitt \& Sibley, 2010). These dimensions of generalized social beliefs about the ideal arrangement of society (habitually referred to as "ideologies") are often labeled social conservatism, right-wing authoritarianism or social-cultural right-wing attitudes on the one hand, and economic conservatism, social dominance orientation or economic-hierarchical right-wing attitudes on the other hand (Duckitt, 2001; Middendorp, 1978).

In the social-cultural domain, right-wing ideology reflects adherence to traditional rules, submission to authorities imposing discipline, and aversion to deviance (Altemeyer, 1981). These social-cultural right-wing attitudes have been proposed to stem from motivational goals related to collective security, social order, social cohesion and conformity (Duckitt, 2001). In the economic-hierarchical domain, right-wing ideology entails the preference for intergroup dominance, social hierarchy and societal inequality (Middendorp, 1978; see also Onraet, Van Hiel \& Cornelis, 2013; Pratto, Sidanius, Stallworth, \& Malle, 1994), which is based on motivational concerns related to control over economic resources, superiority and power (Duckitt, 2001). 
Much research relates both social-cultural and economic-hierarchical right-wing attitudes to various types of negative outgroup attitudes and prejudice, including racism (e.g. Van Hiel \& Mervielde, 2005), sexism (e.g., Roets, Van Hiel, \& Dhont, 2012), and homophobia (e.g., Poteat \& Spanierman, 2010). Moreover, individuals holding right-wing attitudes, especially at the economic-hierarchical level, show greater anti-elderly sentiment (Aosved, Long, \& Voller, 2009; North \& Fiske, 2013), suggesting that they see older people as weak and inferior. The relationship between the social-cultural dimension of right-wing attitudes and ageism is less straightforward, with the few available studies revealing small positive (e.g., North \& Fiske, 2013) or negative associations (Lambert \& Chasteen, 1997). In this regard, one may suspect that simultaneous views of the elderly as respected and relatively conventional on the one hand, but also as disadvantaged and resource-draining on the other hand, elicit ambiguous reactions in people holding social-cultural right-wing attitudes.

In sum, the positive relationship between right-wing attitudes and outgroup prejudice is well-documented for a variety of different outgroups (with the socio-cultural aspect playing a somewhat ambiguous role for older-age outgroups). Moreover, these relationships were found with longitudinal designs (Asbrock, Sibley, \& Duckitt, 2010) and across different countries (Cohrs \& Stelzl, 2010).

\section{The Multilevel Character of Ideologies}

Although social-cultural and economic-hierarchical right-wing attitudes are conceptualized as individual differences, these constructs are embedded within a much broader context of intergroup relations (Pratto et al., 1994). Indeed, an important feature of ideologies is that they are socially shared. Individuals are embedded in societal contexts, and ideological climates can provide social groups, organizations, and even whole societies with a set of unifying, collectively shared norms and values, which guide how individuals within 
these contexts think about, understand, and evaluate other social groups (Cohrs, 2012). This "higher-level" character of ideology offers the opportunity to explore the role of ideological climates in shaping intergroup attitudes. Stangor and Jost (1997) have asserted that, in the intergroup relations literature, higher-level processes are far too often approached only theoretically, and little empirical research has been conducted to explore their normative influence in social phenomena. It is therefore unclear to what extent higher-order contextual variables like ideological climate have an impact beyond the values and beliefs individuals personally endorse on target variables like outgroup attitudes.

Some studies have made use of the presence of radical right-wing parties as an indicator of a conservative climate within a geo-political area, showing that across European countries, the presence of such parties is related to negative attitudes towards immigrants and immigration over and above the variance explained by individuals' own political orientation (Semyonov, Raijman, \& Gorodeisky, 2006). Additionally, two studies conducted in Switzerland revealed that individuals' opposition to anti-racism laws (Sarrasin et al., 2012) and individuals' attitudes towards Muslim women wearing a veil (Fasel, Green, \& Sarrasin, 2013) were predicted by the conservative climate of their municipality (indexed by the results on an earlier referendum), in addition to individual-level conservative values.

However, the presence of particular political parties or referendum results can only serve as a proxy for right-wing ideological climates within a region, and they also do not capture the distinction between the social-cultural and economic-hierarchical dimensions as studied in the literature about right-wing attitudes at the individual level. Fischer (2009) therefore suggested a bottom-up approach to ideological climate by using aggregated individual-level measures of values and beliefs to reflect popular views within a context. The combined effects of the individual and contextual levels have been investigated in several studies studying peer groups. For example, Poteat, Espelage, and Green (2007) found that a 
hierarchy-enhancing social climate within a peer group of friends was related to more negative attitudes among students towards homosexuals. Furthermore, Poteat and Spanierman (2010) reported that aggregated right-wing beliefs of peer groups predicted individuals' racist and homophobic attitudes beyond their personal ideological views.

The theoretical rationale here is that such peer group environments are social contexts in which group norms are developed and enforced through socialization processes that encourage the acceptance of and support for traditional rules, social order and social inequality (Poteat et al., 2007; 2010). Kiesner, Maass, Cadinu and Vallese (2003) further suggested that the salience of such contextual norms leads to the internalization of these norms and the ideological justification for their expressions. In the same vein, theorizing on psychological geography holds that social norms have top-down effects on personality and ideology by shaping life experiences and opportunities (Rentfrow, Gosling, \& Potter, 2008). The basic idea here is that the traditions and daily practices common to an area affect social norms, which in turn affect people's attitudes and behaviors.

This psychosocial environment could, in turn, reinforce the regional social norms and influence the ways in which people in that region think, feel, and behave, even if those tendencies are contrary to their natural dispositions (Rentfrow et al., 2008; see also Crandall \& Eshleman, 2003). In sum, individuals may use their own ideological beliefs as well as those of their fellow citizens to justify their outgroup attitudes. Yet, at the societal level, no published studies to date have investigated such aggregated ideology scores as a measure of right-wing climate in order to investigate its incremental power in the prediction of prejudice.

\section{To a Person X Context Interaction Approach}

Based on the findings we discussed above, there seems to be substantial evidence that right-wing ideological attitudes and right-wing social climates both uniquely contribute to 
individual differences in prejudice. However, for a more complete understanding of outgroup attitudes, the study of the cross-level interaction between individual and society seems vital, and aligns well with the recurrent calls in the field for a more "integrated" (Doise, 1986) or “contextual” (Pettigrew, 1991) social psychology. A most interesting perspective on how such interactions may take form is provided by the interactionism framework (Blumer, 1969), which proposes that strong normative influences may weaken and even "take over" the influence of personal characteristics on an individual's attitudes and behavior. Sniderman, Hagendoorn, and Prior (2004) argued that situational triggers may either galvanize those already concerned about a particular problem, or may mobilize citizens to become worried about a political problem, whether or not they were already predisposed to be concerned.

From a "galvanizing" perspective, in low right-wing climates, almost all individuals (also those with high levels of right-wing attitudes) might be elicited to show less negative outgroup attitudes (because of liberal norm setting), whereas in high right-wing climates, only people high in right-wing attitudes would be prejudiced. An experimental study provided some preliminary support for the galvanizing perspective, showing that especially those with authoritarian predispositions tended to be activated by contextual cues of social threat (Stenner, 2005). Also, a cross-country study indicated that the effect size of authoritarianism on prejudice was higher in countries where inhabitants were more likely to believe that immigrants increase crime rates (i.e., an indicator of a conservative regional norm; Cohrs \& Stelzl, 2010).

A "mobilizing" perspective holds that in low right-wing climates, only people high in right-wing attitudes would be prejudiced, whereas in high right-wing climates, almost all individuals (also those with low levels of right-wing attitudes) might be elicited to show more negative outgroup attitudes (because of conservative norm setting). Consistent with this hypothesis, Nail, McGregor, Drinkwater, Steele, and Thompson (2009) demonstrated in a 
series of experimental studies that threats to the system led liberal individuals to converge to attitudes very similar to those of conservatives. Likewise, national-level exclusionary policies increased opposition against immigration, especially among individuals with egalitarian values (Schwartz, 2007).

Nonetheless, to our knowledge, no studies have explicitly operationalized right-wing climates as aggregated individual-level ideologies and examined the cross-level interaction between right-wing attitudes and climates. Furthermore, whereas some small-scale studies investigated race-based outgroups, no studies have yet been conducted for age-based and gender-based outgroups.

\section{The Present Study}

This study is the first to thoroughly examine whether right-wing ideological climates galvanize individuals high in right-wing attitudes towards more prejudice, or mobilize individuals low in right-wing attitudes towards more prejudice. To ensure the robustness of the results obtained with this multilevel interactionist approach, we investigated the moderating influence of ideological climate in samples at the regional (Study 1) as well as the national (Study 2) level. Moreover, we tested the model for various forms of outgroup attitudes (i.e., anti-elderly, anti-young and anti-immigrant attitudes in Study 1; and antielderly, anti-immigrant and anti-women attitudes in Study 2) to investigate the generalizability of the obtained relationships as well as to identify possible target-specific effects at the individual and group level.

\section{Study 1}

\section{Method}

\section{Data}


Study 1 analyzed data from the fourth round of the European Social Survey (ESS, 2008, http://www.europeansocialsurvey.org). The European Social Survey is an academically driven cross-national survey explicitly developed and vetted to maximize cross-cultural invariance (Davidov et al., 2015). Data were collected by face-to-face interviews and are representative for each country. Round 4 data were collected between September and December 2008 (ESS, 2008) among 56,752 individuals living in 29 European countries (see Online Appendix A). Within each country, NUTS ("Nomenclature des Unités Territoriales Statistiques", or "Classification of Territorial Units for Statistics") can be distinguished. These units delineate within-country regions according to socioeconomic, cultural and historical characteristics, as determined by Eurostat (2003). For example, within Sweden, three NUTS-1 regions are distinguished (East Sweden, South Sweden, and North Sweden). Each of these regions in turn include two or three smaller NUTS-2 regions, such as Stockholm and East Middle Sweden within East Sweden, Småland and the islands, South Sweden, and West Sweden within South Sweden, and North Middle Sweden, Middle Norrland, and Upper Norrland within North Sweden. NUTS-regions were used as higher-level units for this study (see below). ESS classified most respondents at the NUTS-2 level, with the exception of respondents in Belgium, France, Germany, Turkey, and the United Kingdom, who were grouped according to the larger-scale NUTS-1 level. The overall sample hence identified 218 NUTS regions with a mean number of participants per region of 260) ${ }^{1}$.

For the analyses on ageism, we assigned all respondents younger than 50 years to form the 'young' group ( $\left.\mathrm{S}_{\text {young }}, N=30,729\right)$, and investigated their attitudes towards older people

\footnotetext{
${ }^{1}$ We report the results using the original regional codes provided with the ESS data. However, when we reclassified the NUTS- 2 codes into their overarching NUTS-1 codes and conducted all analyses using these superordinate regions ( $N=101$ NUTS-1 regions; mean number of respondents per region $M=556$ ), the pattern of results was similar (i.e., all significant results remained significant).
} 
(i.e., over 70 years). Participants over 50 years formed the 'old' group $\left(\mathrm{S}_{\text {old }}, N=24,841\right)$ and data were analyzed with respect to their attitudes towards young people (i.e. under 30 years). Because the age of 50 is the midpoint between the target groups in the age-related questionnaire items (see below), we selected this cut-off point to delineate the young and the old group and investigate the effects on ageism. Importantly, analyses using different cut-off points (i.e., under $40(N=21,087)$ or under $30(N=11,649)$ for $S_{\text {young, }}$, versus over $60(N=$ $15,342)$ or over $70(N=7343)$ for $\left.S_{\text {old }}\right)$ yielded similar results. Given that the straightforward split of the total sample at age 50 makes use of the maximal amount of data, these results are reported.

To test our multilevel framework for negative attitudes towards ethnic outgroups, we omitted all respondents who had no national citizenship, who had a place of birth outside the country of data collection, or who classified themselves as belonging to a minority ethnic group in their country, resulting in a 'non-immigrant' sample $\left(\mathrm{S}_{\text {non-immigrant }}\right)$ with $N=51,816$.

\section{Measures}

Background characteristics. Means and distributions of age, gender, income and education for each sample are provided in Appendix B ${ }^{2}$.

Individual-level measures. The ESS survey assesses a wide variety of items but usually does not include full-length scales. Therefore, building on previous studies (e.g., Abrams, Russel, Vauclair, \& Swift, 2011; Onraet et al., 2013), we selected relevant items and compiled the best possible measures for our constructs of interest. Because in some cases

\footnotetext{
${ }^{2}$ Running all analyses with or without statistical control for the demographic variables did not
} alter the findings. For clarity reasons, we therefore reported results from the analyses without inclusion of the demographic variables. The results from the analyses including demographics are available upon request with the first author. 
rating scales differed across items, Principal Component Analyses ${ }^{3}$ (PCA) were conducted to compute a single component for every construct, with a mean and standard deviation of 0 and 1, respectively. For all scales, PCA corroborated the one-dimensional nature of the construct. Explained variance and factor loading range for each measure in each sample are displayed in Appendix C.

Social-cultural attitudes. The five items previously used by Kauff, Asbrock, Thörner, and Wagner (2013) were used to operationalize the construct of social-cultural attitudes. These items were "Schools must teach children to obey authority", "People who break the law should be given much harsher sentences than they are these days", "If a man is suspected of planning a terrorist attack in [country], the police should have the power to keep him in prison until they are satisfied he was not involved", "How much like you is this person? It is important to her or him that the government ensures her or his safety against all threats. She or he wants the state to be strong so it can defend its citizens," and "How much like you is this person? She or he believes that people should do what they're told. She or He thinks people should follow rules at all times, even when no one is watching". Respondents answered the first three items on a five-point Likert scale ranging from 1 ("Totally agree") to 5 ("Totally disagree") and the last two items on a six-point Likert scale ranging from 1 ("Very much like me") to 6 ("Not like me at all").

Economic-hierarchical attitudes. For economic-hierarchical attitudes, we combined the two items previously used by Onraet et al. (2013): “The government should take measures to reduce differences in income levels", and "For a society to be fair, differences in people's standard of living should be small”. Respondents answered on a five-point Likert scale

\footnotetext{
${ }^{3}$ We chose PCA to obtain a measure capturing as much of the total variance in the items as possible. Measures based on alternative data reduction methods such as Exploratory Factor Analyses yielded virtually identical results.
} 
ranging from 1 (“Totally agree”) to 5 (“Totally disagree”), with higher values indicating preference for economic and societal inequality.

Left-right political orientation. To include an additional political rather than socialideological indicator of individual right-wing attitudes, we used the following item: "In politics people sometimes talk of "left" and "right". Where would you place yourself on this scale, where 0 means the left and 10 means the right?".

Negative attitudes towards other age groups. Negative attitudes towards other age groups were measured with three items asking participants to describe how they feel with respect to other age groups (Abrams et al., 2011). The items were "Please tell me how important it is for you to be unprejudiced against people of other age groups", "Please tell me how important it is for you to be seen as being unprejudiced against people of other age groups", and "Overall, how negative or positive do you feel towards people of [age group]?". In the 'young' sample, the target age group refers to people over 70, whereas in the 'old' sample, the target group concerns people in their 20s. Respondents answered on a ten-point Likert scale ranging from 1 ("Not at all important/Extremely negative") to 10 ("Extremely important/Extremely positive"). All items were reverse coded.

Negative attitudes towards immigration. Six items measured attitudes towards immigration (Sides \& Citrin, 2007). The first three items read: "To what extent do you think [country] should allow people of the same race or ethnic group as most [country]'s people to come and live here?", “To what extent do you think [country] should allow people of a different race or ethnic group from most [country] people?", and “To what extent do you think [country] should allow people from the poorer countries outside Europe?" Respondents answered on the following four-point Likert scale: 1 ("Allow many to come and live here"), 2 (“Allow some"), 3 (“Allow a few"), and 4 (“Allow none"). The last three items tapped into 
appraisals of the value of immigration: "Would you say it is generally bad or good for [country]'s economy that people come to live here from other countries?", "Would you say that [country]'s cultural life is generally undermined or enriched by people coming to live here from other countries?", and "Is [country] made a worse or a better place to live by people coming to live here from other countries?"). Answers were given on a ten-point Likert scale with 1 corresponding to full agreement with the first (i.e., negative) opinion and 10 to full agreement with the second (i.e., positive) opinion. These three items were reverse coded.

\section{Climate measures.}

Social-cultural climate. Regional indicators of the social-cultural climate within a NUTS-region were obtained by calculating the mean of individual factor scores on socialcultural attitudes of all respondents within a specific region.

Economic-hierarchical climate. To measure the economic-hierarchical climate within a NUTS-region, we averaged individual factor scores on economic-hierarchical attitudes of all respondents within a region.

Left-right political climate. The item on left-right political orientation was also averaged at the NUTS-level so that higher scores refer to a context where the overall political stance tends to be more right-wing.

\section{Data analytic procedure}

We used multilevel modeling (MLM) because respondents (individual level) were nested within regions (social context level). All analyses were performed using SPSS Software (version 22.0; IBM Corp, 2013). For each analysis, we used the following procedure: first, we estimated empty (intercept-only) models which provide insight in the variances at the individual and contextual level. We assessed the intraclass correlations (ICC) for all indicators to ensure that there was substantial between-level variance, justifying the use 
of MLM. All ICCs were medium to large (0.09 for anti-elderly, 0.08 for anti-young, and 0.16 for anti-immigrant attitudes, respectively). During the next phases, all predictors were added to the model (in blocks). At the individual level, we tested the associations of right-wing ideology with negative outgroup attitudes. Next, at the context level, we tested the effect of the right-wing climate. Specifically, we included the relationship between the mean level of right-wing attitudes within the regions and the prejudice indicators at the individual level, while controlling for individual differences in right-wing attitudes. Finally, we analyzed the slope variance, testing whether the relationship between right-wing attitudes and negative outgroup attitudes was significantly different across regions, and whether our indicators of right-wing climate explain (part of) the variance in the slopes.

All independent variables were grand-mean centered around the overall average of the specific sample to control for their compositional effects at the contextual level (Raudenbush \& Bryk, 2002). We used full-information maximum-likelihood estimates with robust standard errors. For none of our variables, the proportion of missing values was higher than $0.6 \%$. We modelled a random coefficient model where the intercept and the slope coefficients vary across regions (see Raudenbush \& Bryk, 2002). Specifically, we investigated three combinations relevant for the multilevel interactionist hypothesis. Our first combination (the 'Social-cultural Model') explored the interaction between social-cultural attitudes and a social-cultural right-wing climate on various prejudice outcomes. The second combination (the 'Economic-hierarchical Model') examined the interaction between economic-hierarchical attitudes and an economic-hierarchical right-wing climate in the prediction of negative outgroup attitudes. The third combination (the 'Left-right Model') investigated the interaction between political left-right orientation and general left-right political climate on our outcomes.

\section{Results}




\section{Main Analyses}

In each subsample, we ran a multilevel hierarchical linear regression analysis to test whether the relationship between right-wing attitudes and negative outgroup attitudes was moderated by right-wing climate. For all analyses, the step-by-step addition of predictors improved the goodness-of-fit statistics of each multilevel model significantly (see Appendix D). Importantly, there was significant variance in the slopes for all models (i.e., Wald Zscores for slope variance were significant; see Appendix E). Correlations among all study variables can be found in Appendix F. Final model results are summarized in Table 1.

Social-cultural model. The first model explored the cross-level interactions between social-cultural attitudes and social-cultural right-wing climate. At the individual level, rightwing attitudes were significantly and positively related to all prejudice outcomes. At the social context level, right-wing climate was positively related to both age-related outgroup attitude measures (but not significantly to anti-immigrant attitudes), indicating that individual negative anti-elderly and anti-young attitudes tended to be higher in regions with a right-wing climate. Most importantly, significant interaction effects between individual attitudes and regional climate emerged (see Table 1, and Figure 1, Panel A-C for cross-level interactions on negative attitudes towards the elderly, towards the young, and towards immigration, respectively). Multilevel simple slope analyses (Raudenbush \& Bryk, 2002) showed that the relationships between right-wing attitudes and prejudiced attitudes were overall rather weak and sometimes non-significant in regions with a high (i.e., 1SD above the mean) right-wing climate $\left(b_{\text {Syoung }}=0.07, p<.001 ; b_{\text {Sold }}=0.03, p=.16 ; b_{\text {Snon-immigrant }}=0.13, p<.001\right)$, whereas the slope lines in regions with a low (i.e., 1SD below the mean) right-wing climate showed a substantial incline $\left(b_{\text {Syoung }}=0.19, p<.001 ; b_{\text {Sold }}=0.19, p<.001 ; b_{\text {Snon-immigrant }}=0.27, p<\right.$ $.001)$. 
Economic-hierarchical model. The second model considered the other dimension of right-wing ideology by investigating cross-level interactions between economic-hierarchical attitudes and an economic-hierarchical right-wing climate. At the individual level, significant and positive within-level effects of right-wing attitudes on all prejudice outcomes were found. At the social context level, significant and positive between-level effects emerged, indicating that negative outgroup attitudes tended to be higher in regions with a high right-wing climate. Furthermore, significant cross-level interaction effects were obtained (see Table 1, and Figure 2, Panel A-C for cross-level interactions on negative attitudes towards the elderly, towards the young, and towards immigrants, respectively). Simple slope analyses indicated that the relationships between economic-hierarchical right-wing attitudes were quite weak in regions with a high right-wing climate $\left(b_{\text {Syoung }}=0.03, p=.001 ; b_{\text {Sold }}=0.03, p=.04 ; b_{\text {Snon-immigrant }}=\right.$ $0.02, p=.06$ ), while the slope lines showed a substantial incline in regions with a low rightwing climate $\left(b_{\text {Syoung }}=0.13, p<.001 ; b_{\text {Sold }}=0.10, p<.001 ; b_{\text {Snon-immigrant }}=0.06, p<.001\right)$.

Left-right model. This model used political orientation as an indicator of right-wing attitudes and right-wing climate. At the individual level, right-wing political orientation was only significantly and positively related to negative attitudes towards immigrants and immigration. At the social context level, right-wing political climate was positively related to negative outgroup attitudes, but none of these effects were significant. Significant cross-level interaction effects were obtained (see Table 1, and Figure 3, Panel A-C for cross-level interactions on negative attitudes towards the elderly, towards the young, and towards immigrants, respectively). Multilevel simple slope analyses revealed that the relationships between right-wing orientation and negative outgroup attitudes were weak in regions with a high right-wing climate $\left(b_{\text {Syoung }}=-0.02, p=.06 ; b_{\text {Sold }}=-0.01, p=.64 ; b_{\text {Snon-immigrant }}=0.07, p<\right.$ .001), where (except in the 'old' sample) the slope lines generally showed a moderate incline 
in regions with a low right-wing climate $\left(b_{\text {Syoung }}=0.05, p<.001 ; b_{\text {Sold }}=0.02, p=.31 ; b_{\text {Snon- }}\right.$ immigrant $=0.14, p<.001)$.

\section{Additional Analyses}

The significant cross-level interactions we obtained could be due to the possibly smaller variance in right-wing ideological attitudes in high right-wing regions as opposed to low right-wing climate regions. We tested this restriction-of-range hypothesis in every sample by 1) exploring the correlation between the mean-level and the standard deviation of ideological attitudes of our 218 NUTS-regions, and 2) entering the standard deviation (SD) of the particular attitude in the first step of our multilevel regression analyses. Correlations between climate and mean SD ranged from $r=-0.14(p<.01)$ to $r=0.13(p<.01)$, indicating that there is no overall restriction of variance in right-wing ideology in regions with a high right-wing climate. Moreover, the inclusion of SDs of ideology into our analyses did not alter the findings, and did not explain negative outgroup attitudes above the other predictors. Additional inclusion of cross-level interactions between individual ideology and contextual SD in ideological climate also did not alter the findings.

Finally, we also tested for outlier effects. One outlier below 3SD for social-cultural right-wing climate was detected in all subsamples (i.e., Bremen, Germany). In the 'young' and 'old' sample, one outlier above 3SD for right-wing political climate emerged (i.e., Jerusalem, Israel in $S_{\text {young }}$, and Podkarpackie, Poland in $S_{\text {old }}$ ). The final model results remained, however, unaltered when excluding these NUTS-regions from either the samplespecific analysis or from all our analyses (i.e., across samples). Results from all additional analyses are available upon request with the first author.

\section{Study 2}


Study 2 aimed to replicate and extend the results of Study 1 by investigating 1) an additional form of prejudice (i.e., sexist attitudes of men towards women) and 2) a broader contextual level (i.e., nations across the world instead of regions across Europe).

\section{Method}

\section{Data}

This study used data from the sixth round of the World Values Survey (WVS, 2012, http://www.worldvaluessurvey.org). The World Values Survey is a global network of social scientists studying social and political life. Like ESS, WVS has made substantial efforts to ensure the equivalence of comparative quantitative data (Welzel \& Inglehart, 2015). Round 6 data were collected in representative national samples between 2010 and 2014 among 74,042 individuals across the world $(N=52$ countries; see Appendix A; mean number of observations per country $M=1,424)$. The WVS- 6 was used because it also provides unique cross-regional data on ageism (i.e., negative attitudes towards the elderly) in addition to data concerning two other types of prejudice, i.e., negative attitudes towards multiculturalism and towards women. To test our person-context interactions for these specific outcomes, we selected three subsamples. Specifically, similar to Study 1, all respondents younger than 50 years formed the 'young' sample ( $\left.\mathrm{S}_{\text {young }}, N=49,370\right)$, and to compose the 'non-immigrant' sample ( $\left.\mathrm{S}_{\text {non-immigrant }}, N=54,775\right)$, we dropped all respondents without national citizenship, with place of birth outside the country of data collection, or with at least one parent being immigrant. To run our analyses concerning negative attitudes towards women, we considered male respondents only (i.e., $\mathrm{S}_{\text {male }}, N=35,032$ ).

\section{Measures}

Background characteristics. Means and distributions of age, gender, income and education for each sample are provided in Appendix B. 
Individual-level measures. Similar to Study 1, we performed PCA to create a single measure for each specific construct. For all scales, PCA corroborated the one-dimensional nature of the construct. Explained variance and range of factor loadings for each measure in each sample are displayed in Appendix C.

Social-cultural attitudes. We selected seven items previously used by Marien and Hooghe (2011) that closely relate to the construct of social-cultural attitudes, especially tapping into conservative, norm-driven moral orientations. Participants were asked the following: "Please tell me for each of the following actions whether you think it can always be justified, never be justified, or something in between: homosexuality, prostitution, abortion, divorce, sex before marriage, suicide and euthanasia. Response scales ranged from 1 ("Never justifiable") to 10 ("Always justifiable"). All items were reverse coded before computing a factor score.

Economic-hierarchical attitudes. We selected three items tapping into economichierarchical attitudes. The first two items were based on Onraet and colleagues (2013). Respondents answered the question "How would you place your views on this scale?" on a ten-point Likert scale ranging from 1 to 10 for two bipolar scales: "Incomes should be made more equal" (1) to "We need larger income differences as incentives for individual effort" (10) and "Government should take more responsibility to ensure that everyone is provided for" (1) to "People should take more responsibility to provide for themselves" (10). The third item was "The state should make people's incomes equal", which ranged from 1 ("Not an essential characteristic of democracy") to 10 (“An essential characteristic of democracy”). The last item was reverse scored so that higher values indicate preference for economic and societal inequality. 
Left-right political orientation. The same measure as in Study 1 was used, asking respondents to place themselves on a 10-point scale with lower values representing the left side of the political spectrum and higher values representing the right side.

Negative attitudes towards the elderly. Negative attitudes towards the elderly were measured with four items: "Older people get more than their fair share from the government", "Older people are a burden on society", "Companies that employ young people perform better than those that employ people of different ages", and "Old people have too much political influence". Respondents answered on a four-point Likert scale ranging from 1 ("Strongly agree") to 4 ("Strongly disagree"). All items were reverse coded.

Negative attitudes towards multiculturalism. Negative attitudes towards multiculturalism were assessed by showing respondents a list of various social groups (see Gorodnichenko \& Roland, 2011) asking them which groups they would not like to have as neighbors. Three of these groups were relevant for our measure: people of a different race, immigrants/foreign workers, and people who speak a different language. The responses were recoded as 0 corresponding to "not mentioned" and 1 corresponding to "mentioned".

Negative attitudes towards women. Similar to Paxton \& Kunovich (2003), sexist attitudes were measured by six items tapping into prejudice against women. The first two read "When jobs are scarce, men should have more right to a job than women", and "If a woman earns more money than her husband, it's almost certain to cause problems". Respondents selected 1 ("Agree"), 2 ("Neither"), or 3 ("Disagree"). The other four items ("When a mother works for pay, the children suffer", "On the whole, men make better political leaders than women do", "A university education is more important for a boy than for a girl", and "On the whole, men make better business executives than women do") were answered on a four-point 
Likert scale ranging from 1 (“Strongly agree”) to 4 ("Strongly disagree”). All items were reverse coded.

Climate measures. Similar to Study 1, individual scores on each indicator of rightwing ideological attitudes within each country were averaged to form national indicators of the right-wing climate. Higher scores refer to a country where, on average, popular beliefs tend to be more right-wing.

\section{Results}

\section{Main Analyses}

Analogous to Study 1, we used MLM because respondents were nested within countries. All ICCs were medium to large ( 0.15 for anti-elderly, 0.13 for anti-immigrant, and 0.35 for anti-women attitudes, respectively), indicating that there was substantial betweenlevel variance. We modelled a random coefficient model in which the intercept and the slope coefficients were allowed to vary across countries. Again, we investigated the 'Social-cultural Model', the 'Economic-hierarchical Model' and the 'Left-right Model'. For all analyses, the step-wise inclusion of predictors improved the goodness-of-fit statistics (see Appendix D) of each model significantly. Importantly, there was significant variance in the slopes for all models (i.e., Wald Z-scores for slope variance were significant; see Appendix E). Correlations among all study variables are shown in Appendix G. Final model results are summarized in Table 2.

Social-cultural model. The first model examined the cross-level interactions between social-cultural attitudes and a social-cultural right-wing climate. At the individual level, rightwing attitudes were positively related to all prejudice outcomes. At the contextual level, rightwing climate was significantly positively related to negative outgroup attitudes towards immigrants and women (but not significantly to attitudes towards the elderly), indicating that 
negative attitudes toward immigrants and women at the individual level tended to be higher in regions with a higher right-wing climate. Most importantly, significant interaction effects between individual right-wing attitudes and national climate emerged (see Table 2, and Figure 4, Panel A-C for cross-level interactions on negative attitudes towards the elderly, towards multiculturalism, and towards women, respectively). Multilevel simple slope analyses showed weak and sometimes non-significant relationships between right-wing attitudes and negative outgroup attitudes in countries with a high (i.e., 1SD above the mean) right-wing climate $\left(b_{\text {Syoung }}=0.04, p=.30 ; b_{\text {Snon-immigrant }}=0.03, p=.18 ; b_{\text {Smale }}=0.09, p<.001\right)$, whereas in countries with a low (i.e., 1SD below the mean) right-wing climate, the slope lines showed a substantial incline $\left(b_{\text {Syoung }}=0.08, p<.001 ; b_{\text {Snon-immigrant }}=0.09, p<.001 ; b_{\text {Smale }}=0.14, p<\right.$ $.001)$.

Economic-hierarchical model. Model 2 investigated cross-level interactions between economic-hierarchical attitudes and an economic-hierarchical right-wing climate. At the individual level, significant and positive within-level effects of right-wing attitudes on all prejudice outcomes were found. At the social context level, a significant, positive betweenlevel effect emerged in the 'male' sample. Sexist attitudes tended to be higher in regions with a higher right-wing climate. Furthermore, significant cross-level interaction effects were obtained (see Table 2, and Figure 5, Panel A-C for cross-level interactions on negative attitudes towards the elderly, towards multiculturalism, and towards women, respectively). Simple slope analyses indicated weak relationships between right-wing attitudes and antielderly and anti-women attitudes in countries with a high right-wing climate $\left(b_{\text {Syoung }}=0.03, p\right.$ $\left.=.08 ; b_{\text {Smale }}=0.06, p=.007\right)$, while the slope lines showed a substantial incline in countries with a low right-wing climate $\left(b_{\text {Syoung }}=0.11, p<.001 ; b_{\text {Smale }}=0.10, p<.001\right)$.

Left-right model. The third model targeted a political indicator of right-wing attitudes and right-wing climate. At the individual level, political orientation was significantly and 
positively related to all outcomes. At the social context level, right-wing political climate was significantly and positively related to negative attitudes in the 'non-immigrant' and the 'male' sample. Moreover, a significant cross-level interaction effect was obtained predicting negative attitudes towards immigration and multiculturalism, and marginally significant cross-level interactions were found for outgroup attitudes in the 'young' and the 'male' sample (see Table 2, and Figure 6, Panel A-C for cross-level interactions on negative attitudes towards the elderly, towards multiculturalism, and towards women, respectively). Multilevel simple slope analyses revealed weak and sometimes non-significant relationships between right-wing

orientation and negative outgroup attitudes in countries with a high right-wing climate $\left(b_{\text {Syoung }}\right.$ $\left.=0.01, p=.12 ; b_{\text {Snon-immigrant }}=0.05, p=.009 ; b_{\text {Smale }}=0.11, p<.001\right)$, and they generally showed a moderate incline in countries with a low right-wing climate $\left(b_{\text {Syoung }}=0.03, p=.04\right.$; $\left.b_{\text {Snon-immigrant }}=0.11, p<.001 ; b_{\text {Smale }}=0.13, p<.001\right)$.

\section{Additional Analyses}

Similar to Study 1, we tested the restriction-of-range hypothesis by investigating the correlations between mean-level ideology and standard deviation (SD) in ideological attitudes of our 52 countries, and by entering the SD of the particular attitude in the first step of our multilevel regression analyses. Correlations between climate and mean SD ranged from $r=-$ $0.13(p<.01)$ to $r=0.15(p<.01)$, indicating that there is no overall restriction of variance in right-wing ideology in regions with a high right-wing climate. Moreover, the inclusion of SD of ideology into our analyses did not alter the findings, and did not explain variance in negative outgroup attitudes above the other predictors. Additional inclusion of cross-level interactions between individual ideology and contextual SD in ideological climate also did not alter the findings. 
Finally, we tested for outlier effects. One outlier below 3SD for social-cultural climate was detected in the 'young' sample (i.e., the Netherlands). In the 'male' sample, one outlier above 3SD for right-wing political climate emerged (i.e., Pakistan). Nevertheless, the final model results were unaffected when excluding these countries from either the sample-specific analysis or from all our analyses (i.e., across samples). Results from all additional analyses are available upon request with the first author.

\section{General Discussion}

Unique in its breadth and the magnitude of its samples, the present research provides a large-scale examination of individual and contextual bases of different forms of outgroup attitudes from a multilevel interactionist perspective. The aim was to apply this perspective on negative attitudes towards outgroups, and more specifically to investigate the additive and interactive contributions of right-wing ideological attitudes and climates herein. The studies tested the interactionism model for several variations of right-wing ideology (social-cultural, economic hierarchical, and left-right political orientation), for multiple forms of outgroup attitudes (i.e., based on age, ethnicity, and gender), and at two different contextual levels (i.e., regional and national), thereby allowing to establish generalizable patterns.

In accordance with previous findings at the individual level (e.g., Asbrock et al., 2010), an overall, positive relationship between right-wing ideology and negative outgroup attitudes emerged across target groups. This association was clearest for the social-cultural and economic-hierarchical dimensions of right-wing ideology (as compared to political orientation). At the contextual level, a right-wing climate within a region (Study 1) or a country (Study 2) was also related to more negative outgroup attitudes of its inhabitants towards the different target groups, over and above the influence of individual-level ideologies. Again, this effect was clearest for the social-cultural and economic-hierarchical dimensions of ideology. 
Most importantly, we obtained several cross-level interactions indicating that the slope of the right-wing ideology - negative outgroup attitude relation is steeper in low right-wing contexts as compared to high right-wing contexts. In Study 1, the individual-level relationship between the two dimensions of right-wing attitudes (social-cultural and economichierarchical) and the three types of outgroup attitudes was significantly weaker in European regions with a high rather than low social-cultural or economic-hierarchical right-wing climate. Moreover, these effects were largely replicated with an indicator of political orientation. Similarly, in Study 2, using country-level indicators of right-wing climate across the world, these person-context interactions on age-based and ethnicity-based outgroup attitudes were replicated. Additionally, we found a similar cross-level interaction on men's negative attitudes towards women. Although the effects in Study 2 were somewhat smaller in size, these replication results yielded strong additional support for the interactionism perspective, not in the least because in Study 2 the number of available contextual units (i.e., 52 countries) was considerably lower than in Study 1 (i.e., 218 NUTS-regions), and the influence of country-level climate is expected to be more diffuse than that of the more proximal, regional environment where people spend most of their time and have their day-today interactions (Van Assche, Roets, Dhont, \& Van Hiel, 2014). Moreover, statistical control for demographic influences (i.e., age, gender, income, and education) and possible statistical artefacts (i.e., the presence of outliers and a restriction of range effect) did not alter the findings, further attesting to their robustness.

\section{Mobilizing Right-Wing Climates}

The conclusion across the different samples and forms of outgroup attitudes is straightforward: right-wing ideological climates moderate the relationship between right-wing ideologies and negative outgroup attitudes. A high right-wing climate appears to eclipse the influence of the individuals' own social beliefs, causing individuals' outgroup attitudes within 
that context to converge towards higher levels, regardless of personal ideology. In contrast, in a low right-wing climate, the relationship between a person's ideological attitudes and outgroup attitudes remains highly significant. These findings thus reveal an interesting asymmetry. In a high right-wing climate, people low in right-wing ideological attitudes are drawn to increased levels of negative outgroup attitudes by the contextual climate, whereas in a low right-wing climate people high on these ideological attitudes do not show a similar tendency to adapt their prejudice levels in the opposite direction.

In other words, a right-wing context seems to have power to influence citizens of all ideologies when it comes to negative outgroup attitudes, whereas a more progressive context does not seem to have the same mobilizing impact on the general population. This observation is reminiscent of other studies in social psychology that have amply illustrated that "the monster of prejudice" is easily evoked in the individual's mind. The classic Robber's Cave studies of Sherif, Harvey, White, Hood, and Sherif (1961) attest to this issue. In these studies, twelve-year-old boys were divided into two groups that had to compete for valuable resources, which was shown to quickly lead to conflict and even intergroup violence. Restoring the peace between the two, however, proved to be much more difficult. Tajfel, Billig, Bundy, and Flament (1971) even showed that the mere presence of an outgroup is enough to elicit prejudice and discrimination, further attesting to the ease with which a negative orientation towards outgroups arises. In line with these classic studies, our results show that the presence of a "prejudice-friendly" climate within a society has the potential to elicit negative outgroup attitudes, even among people who do not have prejudice-prone ideological attitudes.

Sniderman and colleagues (2004) advanced the mobilizing hypothesis to account for the potential of a right-wing context to increase prejudice "across-the-board" (p. 43); that is, among citizens all across the ideological spectrum. To understand the nature of this 
mobilizing effect, we argue that norm setting plays a pivotal role. Social-cultural right-wing climates emphasize conformity and adherence to traditional norms, which may create the perception of greater collective ingroup identity and uniformity of shared norms and values (Cohrs, 2012), especially affecting those who do not already adhere to these norms themselves. The more widely shared and supported these social beliefs become, the more they fuel perceptions of outgroups as threatening and the less likely positive intergroup attitudes will develop (see Fischer, 2009). Likewise, norm setting in economic-hierarchical right-wing climates legitimizes inequality within the societal context, emphasizes widely-shared beliefs of ingroup dominance over outgroups, and hence increases the public support for outgroup intolerance and derogation. Embedding this idea within the Justification Suppression Model (Crandall \& Eshleman, 2003), such shared norms might offer a justifying social context that affords an opportunity for the expression of prejudice, and, hence, prejudiced attitudes "bubble up past suppression” (Crandall \& Eshleman, 2003, p. 421), even among those holding rather liberal economic-hierarchical ideologies.

Building on the works of Sniderman and colleagues (2004) and Crandall and Eshleman (2003), we propose that "popular" negative representations of outgroups within right-wing climates justify the prevailing societal arrangement and, eventually, become so ingrained and embedded within day-to-day interactions that they also influence those low in right-wing attitudes to embrace exclusionary attitudes. Interestingly, when the social norms within a region support outgroup tolerance, only individuals low in right-wing attitudes tend to display tolerant outgroup attitudes. Our reasoning for the smaller (or even non-existent) mobilizing effect of low right-wing climates would be that liberal norms of not expressing prejudice do not affect right-wing individuals to the same degree. Instead, these individuals tend to stick to their personal cognitions, beliefs, and values that serve to justify prejudice.

\section{Generalized Cross-Level Patterns across Various Prejudices}


Notably, the mobilizing effects of right-wing climates generalize across outgroups based on age, ethnicity, and gender. Specifically, the observation that individual differences, social contexts, and their interaction effects yield similar findings for three of the most common forms of negative outgroup attitudes attests to the functional equivalence of all these prejudices in the individual's mind. This finding reminds us of studies that have shown that prejudice generalizes to different ethnic outgroups, and even to unknown groups or fictitious groups (Roets \& Van Hiel, 2011). Moreover, prejudice towards ethnic outgroups also spreads over to other social groups, like women (Roets et al., 2012), physically or mentally impaired people (Akrami, Ekehammar, Claesson, \& Sonnander, 2006), gay people (Poteat \& Spanierman, 2010), and individuals with another religion (Aosved et al., 2009). The present demonstration further extends the idea that the specific target group in itself is only of secondary importance, presenting the first evidence on the functional resemblance of negative outgroup attitudes even in cross-level patterns.

Our results thus corroborate the idea of unity in various negative outgroup attitudes (Allport, 1954; Asbrock et al., 2010), which leads to some remarkable observations, especially with respect to age-based groups. Because social-cultural attitudes reflect conservative and traditional views, one could expect these attitudes to relate to respect for older people, given their potential status as the guardians of conventional, old-fashioned values and traditions. Hence, decreased levels of negative attitudes about the elderly may have been expected (see Lambert \& Chasteen, 1997). However, both at the individual and social context level, right-wing attitudes were positively related to such negative attitudes. It is possible that young individuals adhering to right-wing ideological views consider the elderly as weak and resource-draining, rather than esteemed and honored.

Moreover, the finding of individual, context, and interaction effects on negative attitudes about age groups in both directions (young versus old, and vice versa) is notable. 
Outgroup borders are fluid for this social category and such attitudes can be considered to reflect prejudice towards one's own future or past ingroup (Kogan, 1961; Lambert \& Chasteen, 1997). It seems strange to exhibit negative attitudes towards a social category that one will belong to, or has belonged to oneself. However, other research has found evidence that people may even exhibit prejudice towards their current ingroup. For example, Roets and colleagues (2012) reported that women often show sexism against their own gender group, and argued that prejudice does not stem from group differences, but rather reflect individual differences in people's perspective on the social world (in particular social-cultural and economic-hierarchical attitudes) that stem from their motivated cognitive style.

\section{Limitations, Implications and Directions for Future Research}

Our study holds some notable limitations which we discuss below. First, in our studies, we operationalized ideological climate as the aggregate of self-reported ideology of the inhabitants of a particular area. However, alternative approaches to operationalize ideological climate within a given region may be useful. For example, objective bottom-up measures such as (extreme) right-wing voting behavior (Sarrasin et al., 2012), or top-down measures such as integration policies at the regional or national level (Schlueter, Meuleman, \& Davidov, 2013) could sort a similar mobilizing effect on individuals low in right-wing attitudes.

Importantly, the combination of analyses at a more proximal, regional level within European countries in Study 1, and at a broader, national level across the world in Study 2, showed that the interactionism perspective applies at different scales, demonstrating both the specificity and generalizability of the effects. We acknowledge that the effect sizes in Study 2 were more modest compared to Study 1, possibly due to the lower number (i.e., 52 countries) of context-level units. Note that the even lower number (i.e., 29 countries) of country-level 
units in Study 1 precluded us from performing cross-level interaction analyses between individual-level and country-level ideology. Also, theoretically, norm setting is more likely to take place, and to have the most impact in a fine-grained context as opposed to large context units. Indeed, people spend most of their social time in (within-country) regions and even in cities and neighborhoods. A next step could be to use longitudinal designs in order to detect how climates can change over time, and how such evolutions may affect the individual's outgroup attitudes. Future studies could also include climate-level measures of social norms to test our hypothesis that norm setting serves as the mobilizing mechanism through which a right-wing climate develops and curbs the influence of individual right-wing socialideological attitudes on outgroup attitudes.

Finally, the present studies aimed to meet the recurrent calls for a more integrated and situated theorizing of intergroup dynamics (e.g., Doise, 1986). The finding that right-wing ideological climates instill exclusionary social norms that steer individuals to react more negatively and discriminatory towards outgroups, even when not personally endorsing rightwing attitudes, is certainly most relevant to understand intergroup attitudes and conflict. In particular, it points out the danger of right-wing ideology among citizens reaching a critical mass so as to form a social norm which drags even people who do not endorse the ideology into outgroup derogation. The history of Europe and other regions has taught us how such process may spiral out of control and, in the worst of cases, may end in a society that allows for violent repression or even genocide of outgroups to happen. 


\section{References}

Abrams, D., Russel, P. S., Vauclair, M. \& Swift, H. (2011). Ageism in Europe: Findings from the European Social Survey. London: Age UK. Available at: http://www.ageuk.org.uk.

Adorno, T., Frenkel-Brunswick, E., Levinson, D., \& Sanford, R. (1950). The authoritarian personality. New York: Harper.

Akrami, N., Ekehammar, B., Claesson, M., \& Sonnander, K. (2006). Classical and modern prejudice: Attitudes toward people with intellectual disabilities. Research in Developmental Disabilities, 27(6), 605-617.

Allport, G. W. (1954). The nature of prejudice. Cambridge, MA: Addison-Wesley.

Altemeyer, B. (1981). Right-wing authoritarianism. Winnipeg, Manitoba, Canada: University of Manitoba Press.

Aosved, A. C., Long, P. J., \& Voller, E. K. (2009). Measuring sexism, racism, sexual prejudice, ageism, classism, and religious intolerance: The intolerant schema measure. Journal of Applied Social Psychology, 39(10), 2321-2354.

Asbrock, F., Sibley, C. G., \& Duckitt, J. (2010). Right-wing authoritarianism and social dominance orientation and the dimensions of generalized prejudice: A longitudinal test. European Journal of Personality, 24(4), 324-340.

Blumer, H. (1969) Symbolic interactionism. Perspective and method. Englewood Cliffs, NJ: Prentice Hall.

Cohrs, J. C. (2012). Ideological bases of violent conflict. In L. Tropp (Ed.), The handbook of intergroup conflict (pp. 53-71). New York: Oxford University Press.

Cohrs, J. C., \& Stelzl, M. (2010). Right-wing authoritarianism and social dominance orientation as predictors of host society member's attitudes toward immigrants: Toward understanding cross-national differences. Journal of Social Issues, 66(7), 673-694.

Crandall, C. S., \& Eshleman, A. (2003). A justification-suppression model of the expression and experience of prejudice. Psychological Bulletin, 129(3), 414-446.

Davidov, E., Cieciuch, J., Meuleman, B., Schmidt, P., Algesheimer, R., \& Hausherr, M. (2015). The comparability of measurements of attitudes toward immigration in the European Social Survey. Exact versus Approximate Measurement Equivalence. Public Opinion Quarterly, 79(1), 244-266.

Doise, W. (1986). Levels of explanation in social psychology. New York: Cambridge University Press. 
Duckitt, J. (2001). A dual process cognitive-motivational theory of ideology and prejudice. In M. Zanna (Ed.), Advances in experimental social psychology (Vol. 33, pp. 41113). San Diego: Academic.

Duckitt, J., \& Sibley, C. G. (2010). Personality, ideology, prejudice, and politics: A dualprocess motivational model. Journal of Personality, 78(6), 1861-1894.

ESS Round 4: European Social Survey Round 4 Data (2008). Data file edition 4.3. Norwegian social science data services, Norway - Data archive and distributor of ESS data.

Eysenck, H. (1954). The psychology of politics. London: Routledge.

Fasel, N., Green, E. G. T, \& Sarrasin, O. (2013). Unveiling naturalization: A multilevel study on minority proportion, conservative ideologies and attitudes towards the Muslim veil. Zeitschrift für Psychologie, 221(4), 242-251.

Fischer, R. (2009). Where is culture in cross-cultural research? An outline of a multi-level research process for measuring culture as a shared meaning system. International Journal of Cross-Cultural Management, 9(1),25-49.

Gorodnichenko, Y., \& Roland, G. (2011). Which dimensions of culture matter for long-run growth?. The American Economic Review, 101(3), 492-498.

Hofstede, G. (1980). Culture's consequences. Beverly Hills, CA: Sage.

IBM Corp. Released 2013. IBM SPSS statistics for windows, version 22.0. Armonk, NY: IBM Corp.

Kauff, M., Asbrock, F., Thörner, S., \& Wagner, U. (2013). Side effects of multiculturalism: The interaction effect of a multicultural ideology and authoritarianism on prejudice and diversity beliefs. Personality and Social Psychology Bulletin, 39(3), 305-320.

Kiesner, J., Maass, A., Cadinu, M., \& Vallese, I. (2003). Risk factors for ethnic prejudice during early adolescence. Social Development, 12, 288-308.

Kogan, N. (1961). Attitudes toward old people: The development of a scale and examination of correlates. Journal of Abnormal and Social Psychology, 62(1),44-54.

Lambert, A. J., \& Chasteen, A. L. (1997). Perceptions of disadvantage versus conventionality: Political values and attitudes toward the elderly versus Blacks. Personality and Social Psychology Bulletin, 23(5), 469-481.

Marien, S., \& Hooghe, M. (2011). Does political trust matter? An empirical investigation into the relation between political trust and support for law compliance. European Journal of Political Research, 50(2), 267-291. 
Middendorp, C. (1978). Progressiveness and conservatism. The fundamental dimensions of ideological controversy and their relationship to social class. Den Haag, Paris, and New York: Mouton.

Nail, P. R., McGregor, I., Drinkwater, A. E., Steele, G. M., \& Thompson, A. W. (2009). Threat causes liberals to think like conservatives. Journal of Experimental Social Psychology, 45(4), 901-907.

North, M. S., \& Fiske, S. T. (2013). A prescriptive intergenerational-tension ageism scale: Succession, identity, and consumption (SIC). Psychological assessment, 25(3), 706713.

Onraet, E., Van Hiel, A., \& Cornelis, I. (2013). Threat and right-wing Attitudes: A crossnational approach. Political Psychology, 34(5), 791-803.

Paxton, P., \& Kunovich, S. (2003). Women's political representation: The importance of ideology. Social Forces, 82(1), 87-113.

Pettigrew, T. F. (1991). Normative theory in intergroup relations: Explaining both harmony and conflict. Psychology and Developing Societies, 3(1), 3-16.

Poteat, P., Espelage, D. L., \& Green, H. (2007). The socialization of dominance: Peer group contextual effects on heterosexist and dominance attitudes. Journal of Personality and Social Psychology, 92(6), 1040-1050.

Poteat, V. P., \& Spanierman, L. B. (2010). Do the ideological beliefs of peers predict the prejudiced attitudes of other individuals in the group? Group Processes and Intergroup Relations, 13(4), 495-514.

Pratto, F., Sidanius, J., Stallworth, L. M., \& Malle, B. F. (1994). Social dominance orientation: A personality variable predicting social and political attitudes. Journal of Personality and Social Psychology, 67(4), 741-763.

Raudenbush, S. W., \& Bryk, A. S. (2002). Hierarchical linear models: Applications and data analysis methods ( $2^{\text {nd }}$ ed.). Thousand Oaks, CA: Sage.

Rentfrow, P. J., Gosling, S. D., \& Potter, J. (2008). A theory of the emergence, persistence, and expression of geographic variation in psychological characteristics. Perspectives on Psychological Science, 3(5), 339-369.

Roets, A., \& Van Hiel, A. (2011). The role of need for closure in essentialist entitativity beliefs and prejudice: An epistemic needs approach to racial categorization. British Journal of Social Psychology, 50(1), 52-73.

Roets, A., Van Hiel, A., \& Dhont, K. (2012). Is sexism a gender issue? A motivated social cognition perspective on men's and women's sexist attitudes toward own and other gender. European Journal of Personality, 26(3), 350-359. 
Sarrasin, O., Green, E. G. T., Fasel, N., Christ, O., Staerklé, C., \& Clémence A. (2012). Opposition to antiracism laws across Swiss municipalities: A multilevel analysis. Political Psychology, 33(5), 659-681.

Schlueter, E., Meuleman, B., \& Davidov, E. (2013). Immigrant integration policies and perceived group threat: A multilevel study of 27 Western and Eastern European countries. Social Science Research, 42(3), 670-682.

Schwartz, S. H. (2007). Universalism values and the inclusiveness of our moral universe. Journal of Cross-Cultural Psychology, 38(6), 711-728.

Schwartz, S. H., Melech, G., Lehmann, A., Burgess, S., Harris, M., \& Owens, V. (2001). Extending the cross-cultural validity of the theory of basic human values with a different method of measurement. Journal of Cross-Cultural Psychology, 32(5), 519542.

Semyonov, M., Raijman, R., \& Gorodzeisky, A. (2006). The rise of anti-foreigner sentiment in European societies, 1988-2000. American Sociological Review, 71(3), 426-449.

Sherif, M., Harvey, O. J., White, B. J., Hood, W. R., \& Sherif, C. W. (1961). Intergroup conflict and cooperation: The robbers cave experiment. Norman, $\mathrm{OK}$ : University Book Exchange.

Sides, J., \& Citrin, J. (2007). European opinion about immigration: The role of identities, interests and information. British Journal of Political Science, 37(3), 477-504.

Sniderman, P. M., Hagendoorn, L., \& Prior, M. (2004). Predisposing Factors and Situational Triggers: Exclusionary Reactions to Immigrant Minorities. American Political Science Review, 98(1), 35-49.

Stangor, C., \& Jost, J. IF. (1997). Individual, group and system levels of analysis and their relevance for stereotyping and intergroup relations. In R. Spears. P. Oakes, N. Ellemers, \& S. A. Haslam (Eds.), The social psychology of stereotyping and group life. Oxford, UK Basil Blackwell.

Stenner, K. (2005). The authoritarian dynamic. Cambridge University Press.

Tagiuri, R. (1968). The concept of organizational climate. In R. Tagiuri \& G. H. Litwin (Eds.), Organizational climate: explorations of a concept (pp. 11-32). Boston: Harvard University, Graduate School of Business Administration.

Tajfel, H., Billig, M. G., Bundy, R. P., \& Flament, C. (1971). Social categorization and intergroup behaviour. European Journal of Social Psychology, 1(2), 149-178.

Van Assche, J., Roets, A., Dhont, K., \& Van Hiel, A. (2014). Diversity and out-group attitudes in the Netherlands: The role of authoritarianism and social threat in the neighbourhood. Journal of Ethnic and Migration Studies, 40(9), 1414-1430. 
Van Hiel, A., \& Mervielde, I. (2005). Authoritarianism and social dominance orientation: Relationships with various forms of racism. Journal of Applied Social Psychology, 35(11), 2323-2344.

Welzel, C. \& R. Inglehart (2015). Misconceptions of measurement equivalence: Time for a paradigm shift. World Values Research 8(5), 151-173.

WVS Wave 6: World Values Survey Wave 6 (2010-2014). Official Aggregate v. 20141107. World Values Survey association, aggregate file producer: Asep/JDS, Madrid, Spain. 


\section{Tables}

\section{Table 1}

Unstandardized Estimates (Standard Errors in Brackets) of Multilevel Regression Analyses on Outgroup Attitudes in Study 1 (European Social Survey data)

\begin{tabular}{|c|c|c|c|}
\hline & $S_{\text {young }}$ & $\mathrm{S}_{\text {old }}$ & $\mathrm{S}_{\text {non-immigrant }}$ \\
\hline & $b(\mathrm{SE})$ & $b(\mathrm{SE})$ & $b(\mathrm{SE})$ \\
\hline \multicolumn{4}{|l|}{ Social-cultural Model } \\
\hline Social-cultural attitudes (SCA) & $0.13 * * *(0.01)$ & $0.11 * * *(0.01)$ & $0.20 * * *(0.01)$ \\
\hline Social-cultural climate (SCC) & $0.28 * * *(0.06)$ & $0.24 * * *(0.05)$ & $0.09(0.06)$ \\
\hline SCA X SCC & $-0.16 * * *(0.03)$ & $-0.21 * * *(0.03)$ & $-0.19 * * *(0.03)$ \\
\hline Explained Variance by Level 1/2 & $3.81 \% / 7.95 \%$ & $6.02 \% / 10.61 \%$ & $9.67 \% / 3.91 \%$ \\
\hline Total Explained Variance ${ }^{b}$ & $4.17 \%$ & $6.40 \%$ & $6.18 \%$ \\
\hline Explained Slope Variance & $22.17 \%$ & $20.26 \%$ & $29.14 \%$ \\
\hline \multicolumn{4}{|l|}{ Economic-hierarchal Model } \\
\hline Economic-hierarchical attitudes (EHA) & $0.08 * * *(0.01)$ & $0.07 * * *(0.01)$ & $0.04 * * *(0.01)$ \\
\hline Economic-hierarchical climate (EHC) & $0.26^{* * *}(0.06)$ & $0.14 *(0.06)$ & $0.36^{* * *}(0.06)$ \\
\hline EHA X EHC & $-0.15 * * *(0.03)$ & $-0.11 * * *(0.03)$ & $-0.07 * *(0.02)$ \\
\hline Explained Variance by Level 1/2 & $2.33 \% / 6.34 \%$ & $1.13 \% / 6.79 \%$ & $1.16 \% / 19.33 \%$ \\
\hline Total Explained Variance ${ }^{b}$ & $2.69 \%$ & $1.60 \%$ & $4.03 \%$ \\
\hline Explained Slope Variance & $17.41 \%$ & $15.04 \%$ & $6.80 \%$ \\
\hline \multicolumn{4}{|l|}{ Left-right Model } \\
\hline Right-wing orientation (RWO) & $0.01(0.01)$ & $0.01(0.01)$ & $0.11 * * *(0.01)$ \\
\hline Right-wing climate (RWC) & $0.07(0.04)$ & $0.08(0.06)$ & $0.15(0.11)$ \\
\hline RWO X RWC & $-0.16 * * *(0.04)$ & $-0.10 * *(0.04)$ & $-0.16 * * *(0.05)$ \\
\hline Explained Variance by Level 1/2 & $0.98 \% / 1.39 \%$ & $0.66 \% / 2.82 \%$ & $3.29 \% / 1.29 \%$ \\
\hline Total Explained Variance ${ }^{b}$ & $1.02 \%$ & $0.84 \%$ & $2.97 \%$ \\
\hline Explained Slope Variance & $22.84 \%$ & $5.33 \%$ & $6.65 \%$ \\
\hline
\end{tabular}


Note: ${ }^{a}: p<.10 ; *: p<.05 ; * *: p<.01 ; * * *: p<.001$

b: Total explained variance $=$ explained variance level $1 *(1-\mathrm{ICC})+$ explained variance level $2 *$ ICC.

The outcomes are negative attitudes towards older people in the 'young' sample (left), towards younger people in the 'old' sample (middle), and towards immigration in the 'non-immigrant' sample (right). 


\section{Table 2}

Unstandardized Estimates (Standard Errors in Brackets) of Multilevel Regression Analyses on Outgroup Attitudes in Study 2 (World Values Survey data)

\begin{tabular}{|c|c|c|c|}
\hline & $S_{\text {young }}$ & $\mathrm{S}_{\text {non-immigrant }}$ & $S_{\text {male }}$ \\
\hline & $b(\mathrm{SE})$ & $b(\mathrm{SE})$ & $b(\mathrm{SE})$ \\
\hline \multicolumn{4}{|l|}{ Social-cultural Model } \\
\hline Social-cultural attitudes (SCA) & $0.06 * *(0.01)$ & $0.06 * * *(0.01)$ & $0.12 * * *(0.01)$ \\
\hline Social-cultural climate (SCC) & $0.23(0.09)$ & $0.31 *(0.12)$ & $0.60 * * *(0.12)$ \\
\hline SCA X SCC & $-0.02 *(0.01)$ & $-0.04 * *(0.02)$ & $-0.06 * * *(0.01)$ \\
\hline Explained Variance by Level 1/2 & $7.45 \% / 13.20 \%$ & $13.94 \% / 14.83 \%$ & $10.04 \%$ / $66.86 \%$ \\
\hline Total Explained Variance ${ }^{b}$ & $9.04 \%$ & $14.02 \%$ & $27.65 \%$ \\
\hline Explained Slope Variance & $2.81 \%$ & $3.63 \%$ & $7.53 \%$ \\
\hline \multicolumn{4}{|l|}{ Economic-hierarchal Model } \\
\hline Economic-hierarchical attitudes (EHA) & $0.07 * *(0.01)$ & $0.04 * * *(0.01)$ & $0.08 * *(0.03)$ \\
\hline Economic-hierarchical climate (EHC) & $0.13(0.09)$ & $0.18(0.13)$ & $0.28 *(0.07)$ \\
\hline EHA X EHC & $-0.06 * * *(0.01)$ & $-0.03(0.02)$ & $-0.08 *(0.05)$ \\
\hline Explained Variance by Level 1/2 & $8.15 \% / 9.97 \%$ & $12.63 \% / 0.38 \%$ & $9.97 \% / 9.96 \%$ \\
\hline Total Explained Variance ${ }^{b}$ & $8.66 \%$ & $11.57 \%$ & $9.82 \%$ \\
\hline Explained Slope Variance & $9.52 \%$ & $0.22 \%$ & $9.17 \%$ \\
\hline \multicolumn{4}{|l|}{ Left-right Model } \\
\hline Right-wing orientation (RWO) & $0.02 *(0.01)$ & $0.08 *(0.02)$ & $0.12 * * *(0.02)$ \\
\hline Right-wing climate (RWC) & $0.22(0.11)$ & $0.17 *(0.06)$ & $0.47 *(0.19)$ \\
\hline RWO X RWC & $-0.03^{\mathrm{a}}(0.02)$ & $-0.05 *(0.02)$ & $-0.02^{\mathrm{a}}(0.01)$ \\
\hline Explained Variance by Level 1/2 & $0.92 \% / 12.29 \%$ & $14.57 \% / 4.56 \%$ & $10.40 \% / 19.44 \%$ \\
\hline Total Explained Variance ${ }^{b}$ & $4.07 \%$ & $13.71 \%$ & $13.20 \%$ \\
\hline Explained Slope Variance & $3.37 \%$ & $0.94 \%$ & $2.27 \%$ \\
\hline
\end{tabular}

Note: $:^{\mathrm{a}}: p<.10 ; *: p<.05 ; * *: p<.01 ; * * *: p<.001$

b: Total explained variance $=$ explained variance level $1 *(1-$ ICC $)+$ explained variance level $2 *$ ICC. 
The outcomes are negative attitudes towards older people in the 'young' sample (left), towards multiculturalism in the 'non-immigrant' sample (middle), and towards women in the 'male' sample (right). 